\title{
Effect of tyrosine kinase inhibitor in patients with chronic myeloid leukemia (cytogenetic, molecular response) in Mosul
}

\author{
Khalid NM Al-Khero \\ Department of Medicine, College of Medicine, University of Mosul, Mosul, Iraq. \\ Correspondence: Khalid NM Al-Khero. khalid_kheroo@yahoo.com.
}

(Ann Coll Med Mosul 2018; 40 (2): 1-8).

Received: 22 ${ }^{\text {nd }}$ Oct. 2018; Accepted: $2^{\text {nd }}$ Dec. 2018.

\section{ABSTRACT}

Objective: To evaluate the cytogenetic, molecular response, effect particularly on bone and heart for imatinib and nilotinib respectively in patients with chronic myeloid leukemia $(\mathrm{CML})$.

Methods: The study was conducted on eighty seven patients on imatinib and twenty nine patients on nilotinib as second line treatment who were treated at Ibn-Sena Teaching Hospital /Outpatient Hematology Department were reviewed from April 2002 to April 2014. The Fluorescent in situ hybridization (FISH) analysis was carried on at central authorized laboratory in Baghdad. The reverse transcriptase-polymerase chain reaction (RT-PCR) carried on authorized laboratory initially in Baghdad then in Mosul, (both laboratory using the same standard and sponsored by Novartis). To study the effect of imatinib mesylate on bone mineral density fifty out of 87 patients were enrolled for this purpose. For all the patients ionized calcium, total calcium, serum albumin, serum alkaline phosphatase, serum phosphate, urea, creatinine and serum levels of intact parathyroid hormone measured at baseline, 6 months and 12 months. Dual energy X-ray absorptiometry (DEXA) measurements of the lumbar spine (L2-L4 vertebrae), and femoral neck were performed using a DEXA scanner. For the nilotinib group, all patients had a base-line standard 12-lead electrocardiography (ECG), with a follow-up ECG's performed every 6 months during the study period to assess any occurrence of QT prolongation, ischemic changes, or arrhythmias Noninvasive cardiac imaging was performed using the resting transthoracic Echocardiography (Echo) with its 2-dimentional and M-mode views.

Results: The median duration of CML is 8 years (range 4-12) and the median duration of treatment by the first generation of the brand tyrosine kinase inhibitor is 8 years (range 4-12). Of the 87 patients who were eligible for follow up $86(98.8 \%)$ achieved complete and major cytogenetic response and $86.21 \%$ have complete and major molecular response. For those on nilotinb $68.94 \%$ have complete and major cytogenetic and molecular response. The overall survival rate is $86.20 \%$ at 12 year of imatinib therapy. The 5 years survival rate after nilotinib treatment is $68.94 \%$ (20 out of 29). DEXA analysis revealed no significant changes in L2-L4 lumbar vertebral bone mineral density (BMD) but there is significant change at femoral neck. Prolongation of QTcF was observed in $80 \%$ of patients on nilotinib with a mean of 13.56 millisecond. There were no significant difference in left ventricular ejection fraction \% from the baseline and none of the patient develop major cardiac event.

Conclusion: Complete and major molecular response is $86.20 \%$ on imatinib therapy whereas it is $68.94 \%$ on nilotinib as second line therapy. The overall survival rate is $86.20 \%$ at 12 year of imatinib therapy. The 5 years survival rate after nilotinib treatment is $68.94 \%$. Significant decrease in femoral neck bone mineral density (BMD) observed after 12 month time point. Nilotinib prolonged the QTcF interval by an average of 13.56 millisecond with no adverse cardiac events.

Keywords: CML, Imatinib, Nilotinib, QT interval, DEXA.

$$
\text { تأثثر مثبط كيناز التيروزين في مرضى اللوكيميا النخاعية المزمنة }
$$




\author{
خالا تافع مصطقى الخيرو \\ فرع الطب، كلية الطب، جامعة الموصل، الموصل، العراق
}

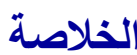

الهدف: تقييم الإستجابة الخلوية الور اثية و الجزييئية، و التأثثر الدو ائي على العظام والقلب لعقاري الايماتنيب ونيلوتينيب على التوالي في المرضى الذين بعانون من سرطان الدم النقوي المزمن. الطرق: شملت هذه الدر اسة سبعة وثمانين مريضا تم قبولهم في وحدة أمر اض الدئن الدم- العيادة الخارجية في مستشفى ابن سينا التعليمي

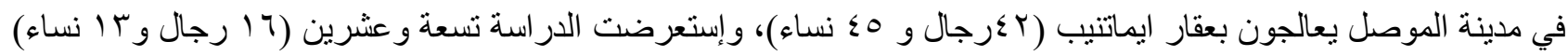

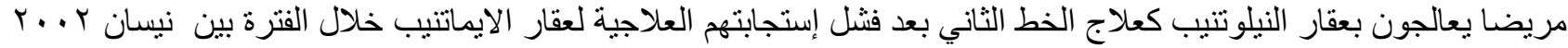
إلى نيسان ع ا • أ. تهجين الفلورسنت في الموقع FISH تم في مختبر مرخص ومعتمد في بغداد. الوقت الحقيقي لتفاعل سلسلة البلمرة المتعددة RT-PCR نفذ إبتداءا في مختبر في بغداد ثم في الموصل (يعتمد المختبران نفس المعيار وبرعاية شركة

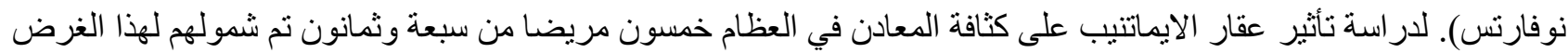

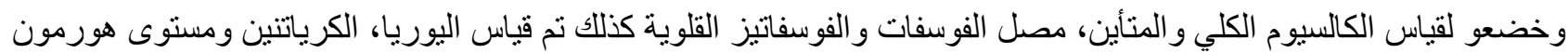
جار الدرقية أجريت الفحوصات في بداية العلاج ثم بعد 7 و Y شهر ا من العلاج. تم إجراء قياسات إمتصاص الأشعة السينية

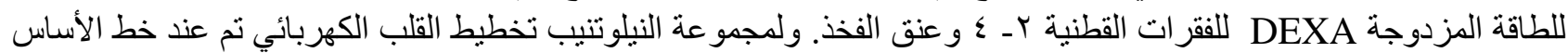
ثم كل 7 أشهر اي زيادة في وقت التئ Q-T التغييرات الاقفارية و إضطر ابات نظم القلب. تم إجراء فحص تخطيط صدى القلب ثنائي

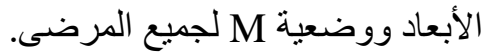

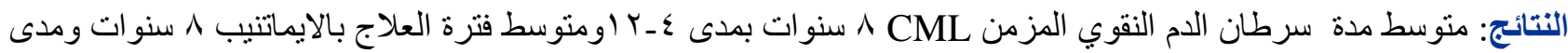

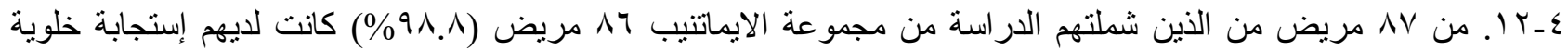

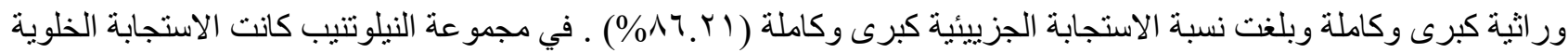

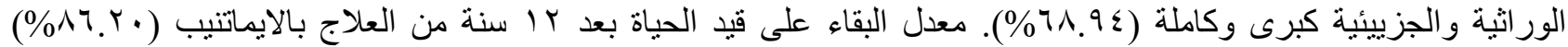

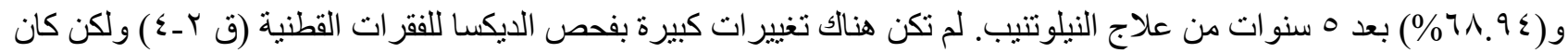

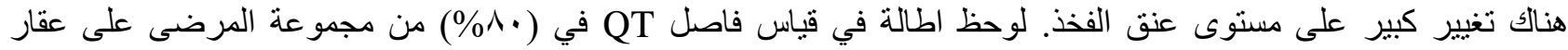

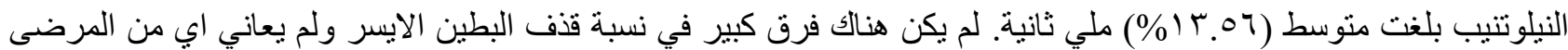

من مضاعفات قلبية شديدة.

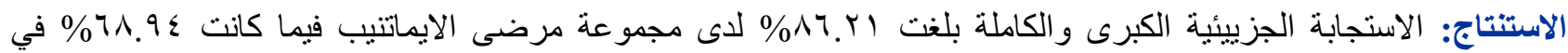

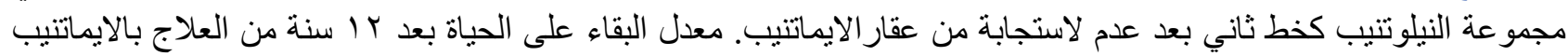

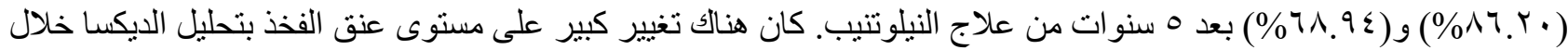

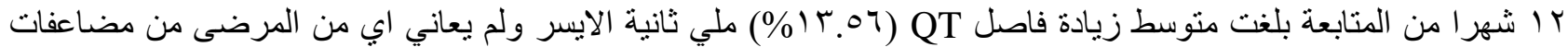

قلبية شديدة.

الكلمات المفتاحية: اللوكيميا النخاعية المزمنة، ايماتتيب، نيلوتنيب، فاصل QT ، ديكسا.

\section{INTRODUCTION}

C hronic myeloid leukemia is a clonal myeloproliferative disorder characterized by the presence of Philadelphia chromosome which represent, a translocation between chromosome 9 and 22, and its product BCR-ABL1 transcript which has been shown to contribute to growth factor independence, increased proliferation, genetic instability and suppression of apoptosis in leukemia. ${ }^{1}$ Tyrosine kinase inhibitor has revolutionized the treatment chronic myeloid leukemia and allow a much faster reduction in Break point cluster region-Abelson 1 ( BCR-ABL1).

The response to TKI can be monitored by hematological, cytogenetic and molecular response, patient with cytogenetic and molecular response as early as 3 months has a better outcome and prognosis than non-responder ${ }^{2}$.

Patient who are resistant or cannot tolerate the first line TKI imatinib still benefit from the second line drug like nilotinib and dasatinib. Fluorescence 
in situ hybridization (FISH) is a highly sensitive molecular genetic technique, which enables to detect breakpoint cluster region - Abelson (BCR$A B L)$ complex and minimal residual disease in all philadelphia positive CML patients not only in metaphase but also in interphase cells. ${ }^{3}$ Reverse transcriptase- polymerase chain reaction (RT$\mathrm{PCR}$ ) by detecting the presence of BCR-ABL1 mRNA is used to monitor the molecular response to $\mathrm{TKI}$, it is capable of detecting low levels of disease and is $>3$ logs more sensitive than conventional cytogenetic ${ }^{4}$. In addition, the RTPCRcan be performed on peripheral blood samples,making it more convenient than bone marrowsampling ${ }^{5}$. Imatinib was available as first line treatment in Iraq and in Mosul since 2002. The FISH analysis was carried on at central authorized laboratory in Baghdad. The reverse transcriptase polymerase chain reaction (RT-PCR) was carried on at authorized laboratory in Baghdad and Mosul.

The aim of this study is to evaluate the cytogenetic, molecular response, effect particularly on bone and heart for imatinib and nilotinib respectively and to achieve this a prospective followup study was conducted.

\section{PATIENTS AND METHODS}

One hundred seventy six patients with chronic phase Philadelphia positive chronic myeloid leukemia on imatinib were registered in the Mosul hematology center since 2002, eighty seven were eligible for review and follow-up, sixty patients were transferred to continue treatment on their original residence in other governorate (Kirkuk, Salahaldien, Anbar and Diyala) and twenty nine patients on nilotinib as second line treatment treated at Ibn-sena teaching hospital /outpatient hematology department were reviewed between April 2002-April 2014.

Eligible patients were 18 years or older, mean age 41.17 year (range 18-75 year), 42 males and 45 females all are in chronic phase CML.The 29 patients on nilotinib, of them 16 were males and 13 were females,mean age 43 year (range 25-70 years) initially treated by imatinib and switched to nilotinib due to primary, secondary failure or drug intolerance. Imatinib mesylate $400 \mathrm{mg}$ was given orally daily. Cytogenetic response (FISH): categories; no cytogenetic response $>95 \% \mathrm{ph}+$, minor cytogenetic response $66 \%-95 \%$ ph+, partial cytogenetic response 36\%-65\% ph+, major cytogenetic response $1 \%-35 \% \mathrm{ph}+$ and complete cytogenetic response $<1 \% \quad(\leq 1 / 200)$ positive Interphase nuclei ${ }^{2}$. The FISH analysis was carried on at central authorized laboratory in Baghdad. Four $\mathrm{ml}$ of peripheral blood in heparinized tube were used to prepare cells in interphase stage according to standard FISH protocol. Hybridization was done using Dual color-Dual fusion Kit from Applied Metasystme (Germany). The test was repeated every 3 months and for those with complete cytogenetic response every 6 months. Escalation of imatinib to $600-800 \mathrm{mg}$ daily was considered for patients who did not obtain a complete hematological response $(\mathrm{CHR})$ after at least 3 months achieve a major cytogenetic response(ph-positive interphases less than 35\%) after 12 months of therapy, or those with cytogenetic relapse (increase of ph-positive interphases by at least $30 \%$ ) ${ }^{6,7}$ The dose of nilotinib is $400 \mathrm{mg}$ twice daily. The Gene Expert by Cephid BCR-ABL Monitor Assay is an automated test for quantifying the amount of BCR-ABL transcript as a ratio of $B C R-A B L-/ A B L 1$ and linked to an international scale (IS) and calibrated to WHO standards. The test carried on authorized laboratory initially in Baghdad then in Mosul, (both laboratory using the same standard and sponsored by Novartis) repeated every 3 months and for those with MMR (4.5 Log) every 6 months then every 12 months later on.Definition of Molecular Response: Major Molecular Response (MMR) corresponds to $0.1 \%$ BCR-ABLIS, the terms Complete Molecular response 4,4.5,5 (CMR4, CMR4.5 and CMR5) have started to be used to indicate levels of disease that are $0.01 \%$ BCRABLIS (4-log reduction from IRIS baseline), $0.0032 \%$ BCR-ABLIS (4.5-log reduction from IRIS baseline) and $0.001 \%$ BCR-ABLIS (5-log reduction from IRIS baseline) respectively ${ }^{8,9}$.

To study the effect of imatinib mesylate on bone mineral density fifty out of 87 patients were enrolled for this purpose. Their age ranges $18-50$ year with a mean age of 33 year. They are 30 male and 20 female. All the patients are on treatment by imatinib for at least 2 year. For all the patients lonized calcium, total calcium, serum albumin, serum alkaline phosphatase, serum phosphate, urea, and creatinine measured at baseline, 6 months and 12 months. Serum levels of intact 
parathyroid hormone using $\mathrm{TOSOH}$ - AIA-360 (Automated Immunoassay Analyzer). DEXA measurements of the lumbar spine (L2-L4 vertebrae), and femoral neck were performed using a DEXA scanner (GE-Lunar Prodigy; GE Lunar Corp., Madison, WI) with encore software version 10.50 (GE Lunar Corp.). The manufacturer's precision errors (coefficient of variation, $1.5,1.8,1.5,1.0$, and $0.5 \%$ for the lumbar spine, femoral neck, sites, respectively) were used to determine the minimum detectable significant change (coefficient of variation \% 2.77) in bone mineral density (BMD) at each site.

Twenty nine patients on nilotinib as second line treatment were followed to evaluate the cardiotoxity.16 male and 13 female with a mean age of 43 year (25-70 years) were included for this purpose. Four of these patients had moderate to severe risk factor for cardiovascular disease, which is defined as $>10 \%$ cardiovascular risk over 10 years based on the Framingham Coronary Heart Disease Risk Score. ${ }^{10}$ It was calculated online using the MD calculator. ${ }^{11}$ All patients had a baseline standard 12-lead electrocardiography (ECG) using the MAC 1600 resting ECG system by GE healthcare, with a follow-up ECG's performed every 6 months during the study period. These ECG's were used to assess any occurrence of QT prolongation, ischemic changes, or arrhythmias while the patient is on nilotinib therapy. Assessment of prolongation of the QT interval was based on the long-QT syndrome diagnostic score 12

The corrected QT interval was calculated using the Fridericia formula (QTcF). ${ }^{13}$ Noninvasive cardiac imaging was performed using the resting transthoracic Echocardiography (Echo) with its 2dimentional and M-mode views, using the MCMD02AA model of Philips Health care product. All patients had their Echo study at the beginning of their Nilotinib and every 6 months during the study time, performed by the same cardiologist. The aim was to assess left ventricular systolic and diastolic functions, and the occurrence of any pericardial disease.

A significant cardiac event was defined as the occurrence of symptomatic arrhythmia, prolongation of $\mathrm{QTCF}>60$ millisecond from baseline, QTcF>500 millisecond, new left ventricular dysfunction, acute coronary syndrome, significant pericardial effusion, or sudden death.

Statistical analysis: The standard statistical methods for the analysis of data, to evaluate the effect of imatinib on bone, were used to determine the mean, standard deviation (SD), paired t-test, in addition to Pearson correlation and Z-test for one proportion.

The statistical results were considered significant at $\mathrm{P} \leq 0.05$ by a statistical program software known as MedCalc version 12.5.0.0: march 29, 2013.

\section{RESULTS}

The median duration of CML is 8 years(range 412) and the median duration of treatment by the first generation of the brand tyrosine kinase inhibitor is 8 years ( range 4-12 Table 1), of the 87 patients who were eligible for follow up 74 (85\%) achieved complete cytogenetic response, 12 (13.8\%) major cytogenetic response and $1(1.2 \%-)$ had minor cytogenetic response (Table 1,2). For those on nilotinb 13 out of $29(44.8 \%)$ have complete cytogenetic response, $7(24 \%)$ major cytogenetic response whereas $9(31 \%)$ patients had no response (Table 2).

Regarding molecular response 75 patients out of 87 (86.20\%) achieved complete and major molecular response whereas $12(13.8 \%)$ patients losses their response to imatinib. For those with complete molecular response $36.78 \%$ have BCRABL $0.001(\log 5)$, 8\% BCR-ABL $0.0032 \%(\log 4.5)$ and $28.78 \%$ BCR-ABL $0.01 \%$ ( $\log 4$ ) reduction in BCR-ABL respectively (Table 3 ). For patients on nilotinib $34.47 \%$ have complete molecular response, $34.47 \%$ major molecular response ,so the overall molecular response is 68.94 , whereas 9 patients have no response to the second line TKI (Table 4).

Twelve out of 87 patient died (10 due to CML) and 2 patient died due to event not related to $\mathrm{CML}$ (shell injury), so the overall survival rate is $86.20 \%$ at 12 year. The 5 years survival rate after nilotinib treatment is $68.94 \%$ (20 out of 29 ).

Decreased serum phosphate levels were observed in $87.88 \%$ of patients after imatinib treatment (pvalue 0.0001), additionally, total calcium levels were significantly lower during the 6-month time point, or 12 month time point of study, compared with baseline levels ( $p$ value 
0.01) whereas ionized calcium were not significantly altered by imatinib treatment (Table 5).

There is increase in mean PTH during the 12 month time point, but this increase is not significant.

DEXA analysis revealed no significant changes in L2-L4 lumbar vertebral BMD but there is significant change at femoral neck (Table 6,7).

For patient on nilotinib, prolongation of QTcF was observed in $80 \%$ with a mean of 13.56 millisecond. This was statistically significant ( $p$ value $=0.03009$ ). However, none of our patients develop a clinically significant prolongation of the QTcF (an increase of $>60$ millisecond from the baseline, or an absolute duration $>500$ millisecond)
Figure 1. There was no significant difference in left ventricular ejection fraction \% from the baseline (Figure 2). None of the patients develop major cardiac event.

Table 1. Demographic characteristic of the patients on Imatinib.

\begin{tabular}{lcc}
\hline Median age (range), years & $41.17(18-75)$ \\
Male \% & 48.27 \\
$\begin{array}{l}\text { Female\% } \\
\text { Median CML duration (range) }\end{array}$ & 81.72 \\
years & $8.02(4-12)$ \\
Mean imatinib dose intensity & $432.14(300-800)$ \\
$\begin{array}{l}\text { (range), mg/d } \\
\text { Median duration of imatinib } \\
\text { treatment (range), years }\end{array}$ & $8.02(4-12)$ \\
\hline
\end{tabular}

Table 2. Cytogenetic response.

\begin{tabular}{lcccc}
\hline \multirow{2}{*}{ Cytogenetic response } & Imatinib 400 mg & Imatinib 600-800 mg & Total & Nilotinib 800 mg \\
\cline { 2 - 5 } CcyR (<1\% ph+) & No. (\%) & No. (\%) & No. (\%) & No. (\%) \\
McyR (1\%-35\% ph+) & $63(88.7)$ & $11(68.75)$ & $74(85.0)^{*}$ & $13(44.83)$ \\
Minor (66\%-95\% ph+) & $8(11.3)$ & $4(25.0)$ & $12(13.8)^{*}$ & $7(24.14)$ \\
Total & --- & $1(6.25)$ & $1(1.2)$ & $9(31.03)$ \\
\hline
\end{tabular}

${ }^{*} \mathrm{P}=0.000$ comparing CcyR Vs. McyR, $(85.0 \%$ Vs. 13.8\%) using Z-test for one proportion.

Table 3. Molecular response to Imatinib.

\begin{tabular}{lcc}
\hline Molecular response & No. & \\
\hline Complete Molecular Response & \\
\hline Log 4 & 25 & 28.74 \\
Log 4.5 & 7 & 8.05 \\
\hline Log 5 & 32 & 36.78 \\
Major Molecular & 11 & 12.64 \\
Response & 12 & 13.79 \\
Loss of response & 87 & 100.00 \\
\hline Total & & \\
\hline
\end{tabular}

Table 4. Molecular response to Nilotinib.

\begin{tabular}{lcc}
\hline Molecular response & No. & $\%$ \\
\hline Complete Molecular Response & & \\
Log 4 & 4 & 13.79 \\
Log 4.5 & 3 & 10.34 \\
Log 5 & 3 & 10.34 \\
Major Molecular & 10 & 34.48 \\
Response & & 31.05 \\
No response & 9 & 100.00 \\
\hline Total & 29 & \\
\hline
\end{tabular}

Table 5. Effects of imatinib on serum calcium and phosphate

\begin{tabular}{lcccccc}
\hline \multicolumn{1}{c}{ Parameter } & $\begin{array}{c}\text { Normal range } \\
(\mathbf{m m o l} / \mathbf{l})\end{array}$ & Baseline & 6 months & P_value & 12 months & P_value \\
\hline Phosphate & $(0.65-1.45)$ & $(0.94-1.70)$ & $(0.45-1.14)$ & 0.0001 & $\left(0.57 \_1.06\right)$ & 0.0001 \\
Total calcium & $(2.10-2.55)$ & $(2.19-2.49)$ & $(2.08-2.39)$ & 0.001 & $\left(2.03 \_2.32\right)$ & 0.01 \\
lonized calcium & $(1.10-1.25)$ & $(1.13-1.33)$ & $(1.11-1.26)$ & NS & $\left(1.13 \_1.25\right)$ & NS \\
\hline
\end{tabular}

Table 6. The effect of imatinib on (L2-L4) BMD.

\begin{tabular}{lcccc}
\hline & \multicolumn{4}{c}{ DEXA study time } \\
\cline { 2 - 5 } DEXA study results & At started time of study & \multicolumn{2}{c}{ After 12 months of start study } \\
& No. & $\%$ & No. & 72 \\
Normal (T-score $>-1)$ & 35 & 70 & 36 & 28 \\
Osteopenia (T-score $>-2.5-<-1)$ & 15 & 30 & 14 & 0 \\
Osteoporosis (T-score $<-2.5)$ & 0 & 0 & 0 & 100 \\
Total & 50 & 100 & 50 & \\
\hline
\end{tabular}


Table 7. The effect of imatinib on (femoral neck) BMD.

\begin{tabular}{lcccc}
\hline \multicolumn{1}{c}{ DEXA study results } & \multicolumn{3}{c}{ DEXA study time } \\
\cline { 2 - 5 } & No. & Start time & \multicolumn{2}{c}{ After 12 months } \\
Normal (T-score $>-1)$ & 19 & 38 & 10 & 20 \\
Osteopenia (T-score $>-2.5-<-1)$ & 31 & 62 & 39 & 78 \\
Osteoporosis (T-score $<-2.5)$ & 0 & 100 & 50 & 2 \\
Total & 50 & & 50 \\
\hline
\end{tabular}

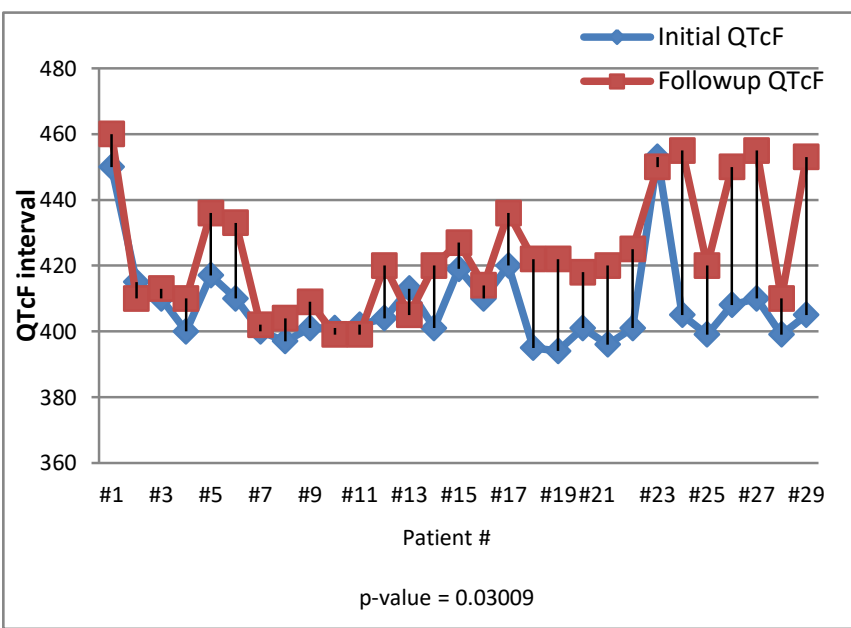

Figure 1. Comparison between initial and follow-up values of $Q T$.

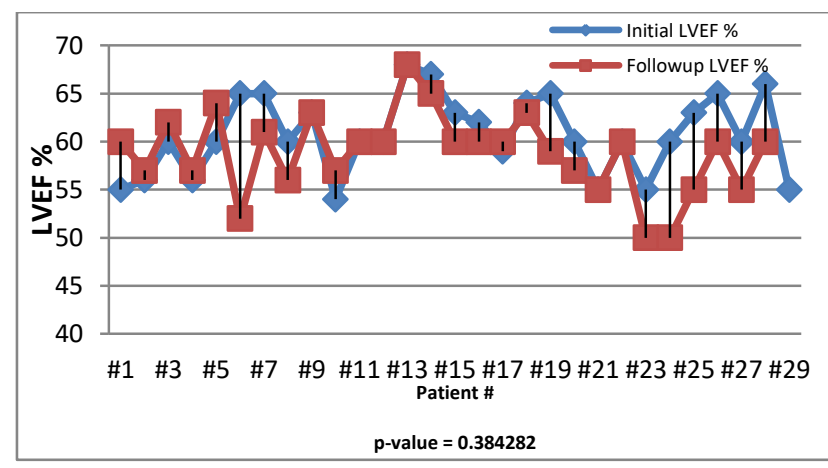

Figure 2. Comparison between initial and follow-up values of $L V E F \%$.

\section{DISCUSSION}

The response to the tyrosine kinase inhibitor in patients with chronic myeloid leukemia in chronic phase are currently monitored by hematological, cytogenetic and molecular test by FISH and PCR$\mathrm{RT}^{14}$. The median duration of $\mathrm{CML}$ is 8 years(range 4-12) and the median duration of treatment by the first generation of the brand tyrosine kinase inhibitor is 8 years (range 4-12), although and due to the circumstances in the country i.e. the sanction and Mosul crisis the brand was not always available and the generic form had been used occasionally instead (Imatib from Cipla), of the 87 patients who were eligible for follow up 74 (85\%) achieved complete cytogenetic response, 12 (13.8\%) major cytogenetic response and 1 (1.2\%- Table 2) had minor cytogenetic response and these finding is in consistent with other studies $^{15,16}$, and for those on nilotinb 10 out of $29(44.8 \%)$ have complete cytogenetic response, 10 (24\%) major cytogenetic response whereas $9(31 \%)$ patients had no response and these finding is in agreement with other study ${ }^{17}$. Regarding molecular response 75 patients out of 87 (86.20\%) achieved complete and major molecular response whereas 12 (13.8\%) patients losses their response to imatinib. For those with complete molecular response $36.78 \%$ have 0.001 $(\log 5), 8 \% 0.0032 \%(\log 4.5)$ and $28.78 \% 0.01 \%$ ( $\log 4)$ reduction in BCR-ABL respectively.

The result is encouraging taking in consideration the horrible situation in the city which is reflected in the treatment of these patients resulting in interruption of their treatment or to use the generic form of the medicine if it is available, so such factor to be considered as a cause of failure or lack of response to $\mathrm{TKI}$ in addition to the well-known criteria and to have different guideline and follow up for patients from country suffering from such event and have limited resources. Of the 29 patients on nilotinib 10 patients achieved complete molecular response $(34.47 \%), 10$ with major molecular response $(34.47 \%)$ whereas 9 patients had no response (31.06\%). The 5 years survival rate after Nilotinib treatment is $68.95 \%$ (20 out of 29).

Twelve out of 87 patient died (10 due to CML) and 2 patient died due to event not related to $\mathrm{CML}$ (shell injury), so the overall survival rate is $86.20 \%$ at 12 year which is lower than previous published data. $^{18}$ 
While CML is not generally associated with a skeletal phenotype, the possibility that the return to normal marrow cellularity or hypo cellularity after imatinib therapy may indirectly affect bone metabolism should be addressed. Because this study could not be placebo-controlled, it cannot be concluded whether the observed effects of imatinib on the skeleton were due to disease remission or were due to direct actions of imatinib on osteoclasts and osteoblasts. However, previous data from CML patients treated with interferon suggest that dysregulated bone remodeling is not a general consequence of disease remission ${ }^{19}$. Consistent with previous studies, imatinib therapy is associated with a decrease in serum phosphate and total calcium (corrected to serum albumin level) and an increase in mean of PTH. The increase in $\mathrm{PTH}$ is not significant in comparison with other studies which compare the baseline of PTH at any point of imatinib therapy ${ }^{20}$ and the studied group was already on imatinib since two years or more. The normal urea and creatinine observed in the studied group exclude renal osteodystrophy as a cause for the change in calcium and phosphate. There is significant decrease in bone mineral density (BMD) at femoral neck whereas there is no change at the level of lumbar vertebrae which in accordance with study by O'Sullivan et $a l^{21}$.

However, the mechanism responsible for this site-specific bone loss remains to be determined possible explanation may be due to the anatomical and cellular composition of the proximal femur.

Nilotinib as targeted therapy have a wellrecognized cardiac toxicity ${ }^{22}$. Twenty four out of 29 patient on nilotinib had a QTcF prolongation between 2-28 millisecond this is in agreement with other study ${ }^{23}$. Our study did not reveal any significant decline in LVEF\% observed by Echo study in line with other studies ${ }^{24}$. None of our patients developed any clinical or ECG evidence of ischemic heart disease, whereas $8 \%$ of patients in the study by T.D Kim et al develop acute coronary syndrome, but no direct link between these event and nilotinib is approved and as reported by other studies patients with vascular events may have other risk factors i.e. hyperglycemia, increase in cholesterol, so nilotinib may aggravate pre-existing atherosclerotic conditions ${ }^{25}$.

\section{CONCLUSION}

The complete cytogenetic response is $85 \%$ for those on imatinib and $86.20 \%$ have complete and major molecular response. The complete cytogenetic response to nilotinib is $44.8 \%$ and $68.95 \%$ having complete and major molecular response. The overall survival rate is $86.20 \%$ at 12 year of imatinib therapy. The 5 years survival rate after nilotinib treatment is $68.96 \%$. Hypophosphatemia, hypocalcaemia and secondary hyperparathyroidism, develops in patients taking imatinib with no change in BMD of L2-L4 vertebrae. Significant decrease in femoral neck BMD observed after 12 month time point.

Nilotinib prolonged the QTcF interval by an average of 13.56 millisecond with no adverse cardiac events.

\section{REFERENCES}

1.Sirard C, Laneuville P, Dick JE. Expression of bcr-abl abrogates factor-dependent growth of human hematopoietic M07E cells by an autocrine mechanism. Blood 1994; (83): 1575-1585.

2.Kantarjian HM, O'Brien S, Cortes JE, et al. Complete cytogenetic and molecular responses to interferon- $\alpha-$ based therapy for chronic myelogenous leukemia are associated with excellent long-term prognosis. Cancer. 2003; (97): 1033-41.

3.T S K Wanl, S K Ma, W Y Au, L C Chan. Derivative chromosome 9 deletions in175 chronic myeloid leukemia: interpretation of a typical D-FISH pattern. Journal of Clinical Pathology 2003; (56): 471474.

4.Branford S, Hughes TP, Rudzki Z. Monitoring chronic myeloid leukaemia therapy by real-time quantitative PCR in blood is a reliable alternative to bone marrow cytogenetics. Br J Haematol 1999; (107): 587-599.

5.Cross NC, Feng L, Chase A,et al. Competitive polymerase chain reaction to estimate the number of BCR-ABL transcripts in chronic myeloid leukemia patients after bone marrow transplantation. Blood 1993; (82): 1929-1936.

6.Kantarjian HM, Cortes JE, O'Brien S, et al. Long-term survival benefit and improved complete cytogenetic and molecular response rates with imatinib mesylate in Philadelphia chromosome-positive chronic-phase chronic myeloid leukemia after failure of interferon-. Blood 2004; 104(7): 1979-1988

7.Kantarjian $\mathrm{H}$, Talpaz $\mathrm{M}$, O'Brien $\mathrm{S}$, et al. Imatinib mesylate for Philadelphia- chromosome-positive, chronic-phase myeloid leukemia after failure of interferon- $\alpha$ : follow-up results. Clin Cancer Res 2002; (8): 2177-2187.

8.Baccarani M, Pileri S, Steegmann JL, Muller M, Soverini S, Dreyling M, et al. Chronic myeloid leukemia: ESMO Clinical Practice Guidelines for diagnosis, treatment and follow-up. Ann Oncol 2012; 23(7): 72-7. 
9.Baccarani M, Deininger MW, Rosti G, et al. European Leukemia Net recommendations for the management of chronic myeloid leukemia. Blood. 2013; 122(6): 872-84. 10.Kantajarian HM, Hochhaus A, Cortes J, et al. Nilotinib is highly active and safe in chronic phase chronic myelogenous leukemia (CML-CP) patients with imatinibresistance or intolerance. Blood 2007;(110): 735.

11.D'Agostino RB, Vasan RS, Pencina MJ,et al. General cardiovascular risk profile for use in primary care: the Framingham Heart Study. doi:10.1161/ circulationaha.107.699579 (accessed 2017).

12.Priori SG, Schwartz PJ, Napolitano C, et a. Risk stratification in the long-QT syndrome. $N$ Engl $J$ Med 2003; (348): 1866-74.

13.Fridericia LS.The duration of systole in the electrocardiogram of normal subjects and of patients with heart disease. Acta Medica Scandinavica 1920;(53):469-486.

14.14.Kalidas M. Kantarjian H. Talpaz M. Chronic myelogenous leukaemia. JAMA 2001;286:40.

15.Deininger M, O'Brien SG, Guilhot $F$, et al. International randomized study of interferon vs. STI571 (IRIS) 8-year follow up: Sustained survival and low risk for progression of events in patients with newly diagnosed chronic myeloid leukemia in chronic phase (CML-CP) treated with imatinib. Blood 2009;114. Abstract \#1126.

16.Kantarjian $\mathrm{H}$, Talpaz M, O'Brien $\mathrm{S}$, et al. Imatinib mesylate for Philadelphia-chromosome-positive, chronic-phase myeloid leukemia after failure of interferon-a: follow-up results. Clin Cancer Res. 2002;8: 2177-2187.

17.Dragana Milojkovic, Emma Nicholson, Jane F. Apperley,et al. Early Prediction Of Success Or Failure Of Treatment With Second-Generation Tyrosine Kinase Inhibitors In Patients With Chronic Myeloid Leukemia. Haematologica February 2010 95: 224-231; Doi: 10.3324/haematol.2009;012781.
18.Massoud M, Sakr R, Kerbage $F$, et al. Analysis of Survival of Patients with Chronic Myeloid Leukemia Treated with Imatinib in the Last 15 Years in Lebanon. Clin Lymphoma Myeloma Leuk. 2017 Jul;17S:S111S115. doi: 10.1016/j.clml.2017.03.294.

19.Fitter S, Dewar AL, Kostakis P, et al2008 Long-term imatinib therapy promotes bone formation in $\mathrm{CML}$ patients. Blood. 2008; 111: 2538-2547.

20.Franceschino A, Tornaghi L, Benemacher $\mathrm{V}$, et al. Alterations in creatine kinase, phosphate and lipid values in patients with chronic myeloid leukemia during treatment with imatinib. Haematologica. 2008; 93:317318.

21.O'Sullivan S, Horne A, Wattie D, et al. Decreased bone turnover despite persistent secondary hyperparathyroidism during prolonged treatment with imatinib. J Clin Endocrinol Metab 2009; 94:1131-1136.

22.Albini A, Pennesi G, Donatelli $F$, et al. Cardiotoxicity of anticancer drugs: the need for cardio-oncology and cardio-oncological prevention. J Natl Cancer Inst. 2010;102(1):14-25.

23.Kantarjian $\mathrm{H}$, Giles $\mathrm{F}$, Wunderle $\mathrm{L}$, et al. Nilotinib in imatinib-resistant CML and Philadelphia chromosomepositive ALL. N Engl J Med. 2006;354:2542-2551.

24.Kim TD, le Coutre $P$, Schwarz $M$, et al. Clinical cardiac safety profile of nilotinib. Haematologica 2012;97(6):883-889.

25.Javid J M, Michael D. Tyrosine Kinase InhibitorAssociated Cardiovascular Toxicity in Chronic Myeloid Leukemia. Journal of clinical oncology. 2015; 33(35): 4210-4217. 